\title{
Correction to: Accuracy of surface strain measurements from transmission electron microscopy images of nanoparticles
}

Jacob Madsen ${ }^{1 *} \mathbb{0}$, Pei Liu², Jakob B. Wagner², Thomas W. Hansen² and Jakob Schiøtz ${ }^{1}$

\section{Correction to: Adv Struct Chem Imag (2017) 3:14} https://doi.org/10.1186/s40679-017-0047-0

Unfortunately, after publication of this article [1], it was noticed that the name of the fifth author was incorrectly displayed as Jakob Schiøz. The correct name is Jakob Schiøtz and can be seen in the corrected author list above. The original article has also been updated to correct this error.

\section{Author details}

${ }^{1}$ Department of Physics, Technical University of Denmark, Fysikvej, Building 311, 2800 Kongens Lyngby, Denmark. ${ }^{2}$ Center for Electron Nanoscopy, Technical University of Denmark, Fysikvej, Building 311, 2800 Kongens Lyngby, Denmark.

\section{Publisher's Note}

Springer Nature remains neutral with regard to jurisdictional claims in published maps and institutional affiliations.

Received: 26 October 2017 Accepted: 2 November 2017 Published online: 07 November 2017

Reference

1. Madsen, J., Liu, P., Wagner, J.B., Hansen, T.W., Schiøtz, J.: Accuracy of surface strain measurements from transmission electron microscopy images of nanoparticles. Adv Struct Chem Imag. 3, 14 (2017). https://doi. org/10.1186/s40679-017-0047-0 provided you give appropriate credit to the original author(s) and the source, provide a link to the Creative Commons license, and indicate if changes were made. 